\title{
Educational Science.*
}

\section{By Sir Robert Blair, LL.D.}

$T^{1}$ value to education of science and the scientific method has hitherto been for the most part indirect and incidental. It has consisted very largely in deductions from another branch of study, namely, psychology, and has resulted for the most part from the invasion into education of those who were not themselves educationists. A moment has now been reached when education itself should be made the subject of a distinct department of science, when teachers themselves should become men of science.

There is in this respect a close analogy between education and medicine. Training the mind implies a knowledge of the mind, just as healing the body implies a knowledge of the body. Thus, logically, education is based upon psychology, as medicine is based on anatomy and physiology. And there the text-books of educational method are usually content to leave it. But medicine is much more than applied physiology. It constitutes an independent system of facts, gathered and analysed, not by physiologists in the laboratory, but by physicians working in the hospital or by the bedside. In the same way, then, education as a science should be something more than mere applied psychology. It must be built up not out of the speculations of theorists, or from the deductions of psychologists, but by direct, definite, ad hoc inquiries concentrated upon the problems of the classroom by teachers themselves. When by their own researches teachers have demonstrated that their art is, in fact, a science, then, and not until then, will the public allow them the moral, social, and economic status which it already accords to other professions. The engineer and the doctor are duly recognised as scientific experts. The educationist should see to it that his science also becomes recognised, no longer as a general topic upon which any cultured layman may dogmatise, but as a technical branch of science, in which the educationist alone, in virtue of his special knowledge, his special training, his special experience, is the acknowledged expert.

Educational science has hitherto followed two main lines of investigation: first, the evaluation and improvement of teachers' methods, and, secondly, the diagnosis and treatment of children's individual capacities.

\section{The Psychology of the Individual Child.}

It is upon the latter problem, or group of problems, that experimental work has in the past been chiefly directed, and in the immediate future is likely to be concentrated with the most fruitful results. The recent advances in "individual psychology"- the youngest branch of that infant science-have greatly emphasised the need, and assisted the development, of individual teaching. The keynote of successful instruction is to adapt that instruction to the individual child. But before instruction can be so adapted the needs and the capacities of the individual child must first be discovered.

\section{A. Diagnosis.}

Such discovery (as in all sciences) may proceed by two methods: by observation and by experiment.

(I) The former method is, in education, the older, At one time, in the hands of Stanley Hall and his followers-the pioneers of the child-study movement -observation yielded fruitful results. And it is

- From the opening address of the President of Section L (Educational Science) delivered at the Cardiff Meeting of the British Association on August 24 .

$$
\text { NO. 2662, VOL. IO6] }
$$

perhaps to be regretted that of late simple observation and description have been neglected for the more ambitious method of experimental tests. There is much that a vigilant teacher can do without using any special apparatus and without conducting any special experiment. Conscientious records of the behaviour and responses of individual children, accurately described without any admixture of inference or hypothesis, would lay broad foundations upon which subsequent investigators could build. The study of children's temperament and character, for example -factors which have not yet been accorded their due weight in education-must for the present proceed upon these simpler lines.

(2) With experimental tests the progress made during the last decade has been enormous. The intelligence scale devised by Binet for the diagnosis of mental deficiency, the mental tests employed by the American Army, the vocational tests now coming into use for the selection of employees-these have done much to familiarise, not school teachers and school doctors only, but also the general public, with the aims and possibilities of psychological measurement. More recently an endeavour has been made to assess directly the results of school instruction, and to record in quantitative terms the course of progress from year to year, by means of standardised tests for educational attainments. In this country research committees of the British Association and of the ChildStudy Society have already commenced the standardisation of normal performances in such subjects as reading and arithmetic. In America attempts have been made to standardise even more elusive subjects, such as drawing, handwork, English composition, and the subjects of the curriculum of the secondary school.

\section{B. Treatment.}

This work of diagnosis has done much to foster individual and differential teaching - the adaptation of education to individual children, or at least to special groups and types. It has not only assisted the machinery of segregation-of selecting the mentally deficient child at one end of the scale and the scholarship child at the other-but it has also provided a method for assessing the results of different teaching methods as applied to these segregated groups. Progress has been most pronounced in the case of the sub-normal. The mentally defective are now taught in special schools, and receive an instruction of a specially adapted type. Some advance has more recently been made in differentiating the various grades and kinds of so-called deficiency, and in discriminating between the deficient and the merely backward and dull. With regard to the morally defective and delinquent little scientific work has been attempted in this country, with the sole exception of the new experiment initiated by the Birmingham justices. In the United States some twenty centres or clinics have been estab. lished for the psychological examination of exceptional children; and in England school medical officers and others have urged the need for " intermediate" classes or schools not only to accommodate backward and borderline cases and cases of limited or special defect (e.g. " number-defect" and so-called "word-blindness"), but also to act as clearing-houses.

In Germany and elsewhere special interest has been aroused in super-normal children. The few investigations already made show clearly that additional attention, expenditure, study, and provision will vield 
for the community a far richer return in the case of the super-normal than in the sub-normal.

At Harvard and elsewhere psychologists have for some time been elaborating psychological tests to select those who are best fitted for different types of vocation. The investigation is still only in its initial stages, but it is clear that if vocational guidance were based, in part at least, upon observations and records made at school instead of being based upon the limited interests and knowledge of the child and his parents, then not only employers, but also employees, their work, and the community as a whole, would profit. A large proportion of the vast wastage involved in the current system of indiscriminate engagement on probation would be saved.

The influence of sex, social status, and race upon individual differences in educational abilities has been studied upon a small scale. The differences are marked; and differences in sex and social status, when better understood, might well be taken into account both in diagnosing mental deficiency and in awarding scholarships. As a rule, however, those due to sex and race are smaller than is popularly supposed. How far these differences, and those associated with social status, are inborn and ineradicable, and how far they are due to differences in training and in tradition can scarcely be determined without a vast array of data.

\section{Teaching Methods.}

The subjects taught and the methods of teaching have considerably changed during recent years. In the more progressive types of schools several broad tendencies may be discerned. All owe their acceptance in part to the results of scientific investigators.

(r) Far less emphasis is now laid upon the disciplinary value of subjects, and upon subjects the value of which is almost solely disciplinary. Following in the steps of a series of American investigators, Winch and Sleight in this country have shown very clearly that practice in one kind of activity produces improvements in other kinds of activities only under very limited and special conditions. The whole conception of transfer of training is thus changed, or (some maintain) destroyed; and the earlier notion of education as the strengthening, through exercise, of certain general faculties has consequently been revolutionised. There is a tendency to select subjects and methods of teaching rather for their material than for their general value.

(2) Far less emphasis is now laid upon an advance according to strict logical sequence in teaching a given subject of the curriculum to children of successive ages. The steps and methods are being adapted rather to the natural capacities and interests of the child of each age. This genetic point of view has received great help and encouragement from experimental psychology. Binet's own scale of intelligence was intended largely as a study in the mental development of the normal child. The developmental phases of particular characteristics (e.g. children's ideals) and special characteristics of particular developmental phases (e.g. adolescence) have been elaborately studied by Stanley Hall and his followers. Psychology, indeed, has done much to emphasise the importance of the post-pubertal period-the school-leaving age, and the years that follow. Such studies have an obvious bearing upon the curriculum and methods for our new continuation schools. But it is, perhaps, in the revolutionary changes in the teaching methods of the infants' schools-changes that are already profoundly influencing the methods of the senior department-that the influence of scientific study has been most strongly at work.
(3) Increasing emphasis is now being laid upon mental and motor activities. Early educational practice, like early psychology, was excessively intellectualistic. Recent child-study, however, has emphasised the importance of the motor and of the emotional aspects the child's mental life. As a consequence, the theory and practice of education have assumed more of the pragmatic character which has characterised contemporary philosophy.

The progressive introduction of manual and practical subjects, both in and for themselves, and as aspects of other subjects, forms the most notable instance of this tendency. The educational process is assumed to start not from the child's sensations (as nineteenth-century theory was so apt to maintain), but rather from his motor reactions to certain perceptual objects-objects of vital importance to him and to his species under primitive conditions, and therefore appealing to certain instinctive impulses. Further, the child's activities in the school should be not, indeed, identical, but continuous, with the activities of his subsequent profession or trade. Upon these grounds handicraft should now find a place in every school curriculum. It will be inserted both for its own sake and for the sake of its connections with other subjects, whether they be subjects of school life, of after life, or of human life generally.

(4) As a result of recent psychological work, more attention is now being paid to the emotional, moral, and aesthetic activities. This is a second instance of the same reaction from excessive intellectualism. Education in this country has ever claimed to form character as well as to impart knowledge. Formerly this aim characterised the public schools rather than the public elementary schools. Recently, however, much has been done to infuse into the latter something of the spirit of the public schools. The principle of self-government, for example, has been applied with success not only in certain elementary schools, but also in several colonies for juvenile delinquents. And in the latter case its success has been attributed by the initiators directly to the fact that it is corollary of sound child-psychology.

Bearing clusely upon the subject of moral and emotional training is the work of the psycho-analysts. Freud has shown that many forms of mental inefficiency in later life-both major (such as hysteria, neurosis, certain kinds of "shell-shock," etc.) and minor (such as lapses of memory, of action, slips of tongue and pen)-are traceable to the repression of emotional experiences in earlier life. The principles themselves may, perhaps, still be regarded as, in part, a matter of controversy. But the discoveries upon which they are based vividly illustrate the enormous importance of the natural instincts, interests, and activities inherited by the child as part of his bio logical equipment; and, together with the work done by English psychologists such as Shand and McDougall upon the emotional basis of character, have already had a considerable influence upon educational theory in this country.

(5) Increasing emphasis is, now being laid upon freedom for individual effort and initiative. Here, again, the corollaries drawn from the psycho-analytic doctrines as to the dangers of repression are most suggestive. Already a better understanding of childnature has led to the substitution of "internal" for "external" discipline; and the predetermined routine demanded of entire classes is giving way to the growing recognition of the educational value of spontaneous ellorts initiated by the individual, alone or in social co-operation with his fellows.

In appealing for greater freedom still, the new psychology is in line with the more advanced educa- 
tional experiments, such as the work done by Madame Montessori and the founders of the Little Commonwealth.

(6) The hygiene and technique of mental work is itself being based upon scientific investigation. Of the numerous problems in the conditions and character of mental work generally, two deserve special mention-fatigue and the economy and technique of learning.

But of all the results of educational psychology, perhaps the most valuable is the slow but progressive inculcation of the whole teaching profession with a scientific spirit in their work, and a scientific attitude towards their pupils and their problems. Matter taught and teaching inethods are no longer exclusively determined by mere tradition or mere opinion. They are being based more and more upon impartial observation, careful records, and statistical analysisoften assisted by laboratory technique- of the actual. behaviour of individual children.

\section{Popular Relativity and the Velocity of Light. ${ }^{1}$}

\section{By Sir Oliver Lodge, F.R.S.}

IN using the phrase "popular relativity" I indicate that what I am criticising is not Einstein's equations-which seem to have justified themselves by results-but some of the modes of interpreting them in ordinary language. Especially do I attack that proposition which asserts that to every observer the velocity of light will not only be constant in reality, but will also superficially appear constant even when he ignores his own motion through the light-conveying medium-a proposition or postulate or axiom which has been shown to lead to curious and, as I think, illegitimate complications, threatening to land physicists in regions to which they have no right of entry, and tempting them to interfere with metaphysical abstractions beyond their proper ken.

Not that a physicist's proper ken is limited to what he immediately observes; he is entitled, and indeed required, to interpret appearances rationally by taking into account every relevant adventitious circumstance, including complications due to his own unobserved, and perhaps unobservable, travel through space.

In a relativity discussion at the Physical Society recently a member is reported to have asked the pertinent question: "Does an observer merely observe, or does he think as well?" If he thinks, I urge that he can allow for changes in his measuring instruments and any other consequences of possible motion, and can refrain from making deductions about space and time on the strength of experiments on matter.

He will know that his senses are material senses, and that all his experiments are made ultimately by their aid. He will know that he can only experiment even on the æther of space indirectly by means of matter, for he has no other means of getting a grip on it. Possibly he may be unable to grip it even thus, but matter gives him his only chance; he certainly cannot experiment on abstractions like space and time.

On the basis of material experiments he may be able to make deductions or draw inferences about the æther, because that certainly has some inter-relations with matter; but it is probably illegitimate. on the basis of material experiments, to make deductions about space and time. at all; they are not likely to be affected by anything that matter can do, and it is only matter with which we can directly deal.

The relation between space and time that represents the velocity of light gives us directly one property of the æther, viz. the product of its electric and magnetic constants, both of which separately are at present unknown. Every student who accepts the æther of space as a reality is probably ready to admit that the velocity of light through free æther is an absolute

1 The substance of this cuntroversial note was communica ed to Section A

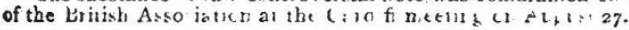
NO. 2662 , VOL. IO6] constant, not dependent on anything that either the observer or the source is doing, has done, or may do.

But this admission has been erected into a fetish by the theory of relativity, at least when expressed in ordinary words, and is interpreted as requiring that to every observer, whatever he may be doing, the velocity of light in every direction will appear the same.

That is not only a different, it is a contradictory, proposition. Given the constancy of the real velocity of light-if an observer travel to meet it, it must appear to arrive more quickly than if he travel away from it, provided he has any means of making the observation at all. $\mathrm{He}$ may be unable to make the observation, but suppose he can make it, say by the aid of Jupiter's satellites, and detected a discrepancy, he need not infer any real change in the velocity of light; because, if he thinks, he can attribute any observed difference to his own motion, and thereby emerge with clear and simple views. If he sets out with the gratuitous notion that he can never become aware of his own motion, or that his own motion has no meaning, he will indeed encounter a puzzling universe, and will presently long for a Copernicus to unravel the subjective complexities of observation.

But it may well be extremely difficult for an observer to measure the velocity of light through the æther except with the aid of some return signal which the æther likewise has to transmit in the opposite direction; and in that case he may find that the to-and-fro pair of journeys take exactly the same time in every direction.

This, as everyone knows, has been done for a toand-fro journey of a beam of light. And the timing is exact, not only to the first order of small quantities, as might readily be expected, but to the second order also-an exactitude which, if rigid unchangeable materials could be used, would not be expected, and ought not to occur. But if the dimensions of the material object used as the foundation-stone of his apparatus are subject to change by reason of motion, and if the changes are in accordance with the electrical theory of matter, as suggested by FitzGerald and elaborated by Lorentz, then everything becomes clear again until we come to astronomical and gravitational applications, and the precisely negative result of Michelson and Morley is precisely explained.

A mathematical doctrine of relativity may be based upon this experimental result, and may be convenient for reasoning purposes, but no such doctrine is required by the facts. The facts are patient of the doctrine; they do not compel it, nor do they justify it. Any comprehensive mathematical expression is liable to permit other modes of interpretation, as well as the simplest and truest or the one most directly applicable to the problem in hand. It is devised to cover one set of facts, but in its generality it is apt 